\title{
Co-Based Heterogeneous Catalysts from Well-Defined $\alpha-$ Diimine Complexes: Discussing the Role of Nitrogen
}

Dario Formenti, $\left.{ }^{[a,}, b\right] \ddagger$ Francesco Ferretti, ${ }^{[a] \ddagger}$ Christoph Topf ${ }^{[b],}{ }^{1}$ Annette-Enrica Surkus, ${ }^{[b]}$ Marga-Martina Pohl, ${ }^{[b]}$ Jörg Radnik, ${ }^{[b]}$ Matthias Schneider, ${ }^{[b]}$ Kathrin Junge, ${ }^{[b]}$ Matthias Beller ${ }^{[b] *}$ and Fabio Ragaini ${ }^{[a] *}$

[a] Dipartimento di Chimica - Università degli Studi di Milano, Via C. Golgi 19, 20133 Milano - Italy; E-mail: fabio.ragaini@unimi.it

${ }^{[b]}$ Leibniz-Institut für Katalyse e.V. an der Universität Rostock, Albert-Einstein-Straße 29a, 18059 Rostock Germany; E-mail: matthias.beller@catalysis.de

${ }^{1}$ Present address: Institut für Katalyse - Johannes Kepler Universitat Linz, Altemberger Straße 69, 4040 Linz - Austria

${ }^{\ddagger}$ These authors contributed equally to this work.

Abstract: Ar-BIANs and related $\alpha$-diimine Co complexes were wet impregnated onto Vulcan ${ }^{\circledR}$ XC 72 R carbon black powder and used as precursors for the synthesis of heterogeneous supported nanoscale catalysts by pyrolysis under argon at $800^{\circ} \mathrm{C}$. The catalytic materials feature a core-shell structure composed of metallic $\mathrm{Co}$ and $\mathrm{Co}$ oxides decorated with nitrogen-doped graphitic layers (NGr). These catalysts display high activity in the liquid phase hydrogenation of aromatic nitro compounds $\left(110{ }^{\circ} \mathrm{C}, 50\right.$ bar $\left.\mathrm{H}_{2}\right)$ to give chemoselectively substituted aryl amines. The catalytic activity is closely related to the amount and type of nitrogen atoms in the final catalytic material, which suggests a heterolytic activation of dihydrogen.

Keywords: cobalt, hydrogenation, nitro compounds, kinetic, heterolytic activation

1. Introduction

Catalysis is a key-technology for the manufacturing of all kinds of bulk and fine chemical products. It allows for producing chemicals avoiding the formation of undesired and useless stoichiometric side products which leads to additional cost and energy consumption [1-3]. Many of the industrially relevant catalytic processes in the fine chemical industry are still based on expensive and rare late transition metals such as Pd, Pt, Rh, Ru and Ir [4,1-5]. Although these metals exhibit very good catalytic performance for advanced organic substrates, the decreasing availability of these elements requires the development of efficient alternative metal-based catalysts [6]. In this regard, the design of catalytic systems based on abundant and biocompatible metals is an important goal for the implementation and progress of green and sustainable chemistry. Hence, transition metals such as $\mathrm{Fe}, \mathrm{Co}$ and $\mathrm{Cu}$ are ideal candidates, which meet these requirements [7-10]. As a matter of fact, these elements are among the most abundant metals in the Earth's upper crust, thus being readily accessible [11]. Recently, heteroatom-doped carbon materials attracted major interest in the field of metal supported heterogeneous catalysts for both chemical synthesis [12-14] and/or energy-relevant transformations [15, 16]. Indeed, doping graphene with heteroatoms such as $\mathrm{N}, \mathrm{B}, \mathrm{P}$, or $\mathrm{S}$ leads to a radical modification of the electronic properties of both the support and the supported metal [17-19]. Consequently, it is possible to modify the activity and adjust the selectivity of the final catalytic material towards the desired transformation. Among the various dopants, nitrogen attracted most interest [15, 20-22]. and applications of transition metal/N-doped graphene (NGr) based catalytic systems ranges from oxygen reduction reactions (ORR) [23-26], hydrogen evolving reactions (HER) [27, 28], photocatalysis [29, 30], oxidation [31-38], and reduction [39-44] reactions of organic 
molecules, C-C bond formation [45] to many others [46-51]. Hence, merging rationally-designed suitable modified supports with cheap transition metals permits access to the design of active, selective and cheap catalytic materials thus allowing to match or to outperform noble-metal-based catalysts. During the last three years, some of us reported the preparation of active and selective NGr-decorated Co-based catalysts from the pyrolysis of in situ generated 1,10-phenanthroline (Phen) metal complexes using Vulcan ${ }^{\circledR}$ XC $72 \mathrm{R}$ carbon [52-60], ceria [61] or $\alpha$-alumina as supports [62]. Some of the obtained nanoscale catalysts exhibit a core-shell architecture in which a Co metallic core is enveloped by an oxidic sheath composed of $\mathrm{CO}_{3} \mathrm{O}_{4}$. In addition, this oxidic shell is augmented by layers of NGr derived from the thermal decomposition of the Phen ligand. Nevertheless, from an economical point of view, phenanthroline is expensive and its functionalization requires multistep fair-yielding transformation procedures. Thus, we were interested in using other, more easily tunable, nitrogen compounds. In this respect, chelating $\alpha$-diimines, especially ArBIAN ligands, are widely used in transition-metal catalysed reactions [63]. As the starting materials are inexpensive (acenaphthenequinone and a variety of aromatic or aliphatic amines), it is possible to prepare a large number of ligands with different electronic and steric properties. This allows for the synthesis of tailor-made transition-metal based catalysts. Nevertheless, apart from a traditional immobilized complexes [64], to the best of our knowledge, no examples of their use as heterogeneous catalysts precursors are known. Herein, we report for the first time that Ar-BIANs and related ligands are able to generate efficient $\mathrm{Co} / \mathrm{NGr}$ catalysts for the hydrogenation of aromatic nitro compounds.

\section{Experimental}

\subsection{Synthesis of the ligands}

Concerning the synthesis of the ligands, all the reactions were carried out under a nitrogen atmosphere using standard Schlenk techniques. All glassware and magnetic stirring bars were kept in an oven at $120^{\circ} \mathrm{C}$ for at least two hours and were cooled to room temperature under vacuum prior to use. $\mathrm{CDCl}_{3}$ used for the NMR experiments was filtered on basic alumina and stored under nitrogen over $4 \AA$ molecular sieves. Chemicals and solvents were purchased from Sigma Aldrich, Alfa Aesar or Tokyo Chemical Industry. Seven different ligands were prepared (L1-L7) following protocols previously reported by some of us (for the preparation of L1, L2, L4, L5 see Supporting Information) [65]. Ligand L3 has been known for more than one century [66] and its synthesis was performed adapting a procedure previously described in the literature [67]. Concerning the preparation of ligand $\mathbf{L 6}$, its synthesis was adapted from that previously reported by some of us [68]. Finally, L7 was synthesized adapting a procedure reported many years ago [66]. The detailed protocols for the preparation of the seven ligands are reported in the Supporting Information.

\subsection{General analysis and characterization methods}

TEM measurements were performed at $200 \mathrm{kV}$ with an aberration-corrected JEM-ARM200F (JEOL, Corrector: CEOS). The microscope is equipped with a JED-2300 (JEOL) energy-dispersive X-ray spectrometer (EDXS) for chemical analysis. The sample was deposited without any pre-treatment on a holey carbon supported Cu-grid (mesh 300) and transferred to the microscope. The High-Angle Annular Dark Field (HAADF) and Annular Bright Field (ABF) images were recorded with a spot size of approximately $0.1 \mathrm{~nm}$, a probe current of $120 \mathrm{pA}$ and a convergence angle of $30-36^{\circ}$. The collection semi-angles for HAADF and ABF were 70-170 mrad and 11-22 mrad, respectively.

XPS data were obtained with a VG ESCALAB220iXL (ThermoScientific) with monochromatic Al Ka (1486.6 $\mathrm{eV}$ ) radiation. The electron binding energies $\mathrm{EB}$ were obtained without charge compensation. For quantitative analysis, the peaks were deconvoluted with Gaussian-Lorentzian curves, the peak area was divided by a sensitivity factor obtained from the element specific Scofiled factor and the transmission function of the spectrometer. 
XRD pattern of the materials were recorded on a Panalytical X'Pert Pro diffractometer in reflection mode with $\mathrm{Cu} K \alpha$ radiation ( $\lambda=1.5406 \AA$ ) and a silicon strip detector ( $X^{\prime}$ Celerator).

NMR spectra of ligands and isolated anilines were recorded on a Bruker Avance DRX 300 or on a Bruker Avance DRX 400 operating at 300 and $400 \mathrm{MHz}$, respectively.

$\mathrm{CHN}$ analyses were performed using a Leco Microanalysator TruSpec or a PerkinElmer $2400 \mathrm{CHN}$. Metal content of the catalysts was determined by atom absorption spectroscopy using a PerkinElmer AAS Analyst 300 after fusion melts and acidic dissolving of the sample.

TPR $-\mathrm{H}_{2}$ measurements were conducted using a Micrometrics Autochem II 2920 instrument equipped with a TCD detector. The experiment run was carried out from $36{ }^{\circ} \mathrm{C}$ to $700{ }^{\circ} \mathrm{C}$ in a $5 \% \mathrm{H}_{2} / \mathrm{Ar}$ flow $\left(20 \mathrm{~cm}^{3}\right.$ $\mathrm{min}^{-1}$ ) with a heating rate of $10 \mathrm{~K} \mathrm{~min}^{-1}$.

\subsection{Catalysts preparation}

The procedure was adapted from that reported for the synthesis of Co/Phen based catalysts [58]. Cobalt(II) acetate tetrahydrate was added to absolute ethanol $(40 \mathrm{~mL}$ of EtOH for $1 \mathrm{mmol}$ of $\mathrm{Co}(\mathrm{OAc})_{2} \cdot 4 \mathrm{H}_{2} \mathrm{O}$ ) and stirred until complete solubilization (10 min., formation of a clear purple solution). Then the ligand $(2 \mathrm{mmol})$ was added (color change to deep red) and the resulting solution was stirred at $60{ }^{\circ} \mathrm{C}$ for $\mathbf{2} \mathrm{h}$. Owing to their scarce solubility in EtOH, ligands $\mathbf{L} \mathbf{2}$ and $\mathbf{L 7}$ were initially solubilized in the minimum amount of inhibitor-free THF and then dropwise added to a solution of $\mathrm{Co}(\mathrm{OAc})_{2} \cdot 4 \mathrm{H}_{2} \mathrm{O}$ in EtOH. After that, VULCAN XC $72 \mathrm{R}^{\otimes}\left(1.392 \mathrm{~g}\right.$ for $1 \mathrm{mmol}$ of $\left.\mathrm{Co}(\mathrm{OAC})_{2} \cdot 4 \mathrm{H}_{2} \mathrm{O}\right)$ was portionwise added during about 30 min and the suspension was stirred at $25^{\circ} \mathrm{C}$ for $18 \mathrm{~h}$. Then, the solvent was removed and the obtained solid was dried for 4 hours under vacuum, grinded to a very fine powder and finally transferred into a ceramic crucible, equipped with a lid, and placed in the pyrolysis oven. The oven was evacuated to ca. $5 \mathrm{mbar}$ and then flushed with argon. Afterwards, it was heated to $800{ }^{\circ} \mathrm{C}$ at a rate of $25^{\circ} \mathrm{C}$ per minute and held at $800{ }^{\circ} \mathrm{C}$ for 2 hours under $\mathrm{Ar}$ atmosphere. Finally, heating was stopped and the oven was cooled down to room temperature. During the whole process, a constant flux of argon through the oven was maintained. The elemental analyses of the prepared materials are reported in the Supporting Information.

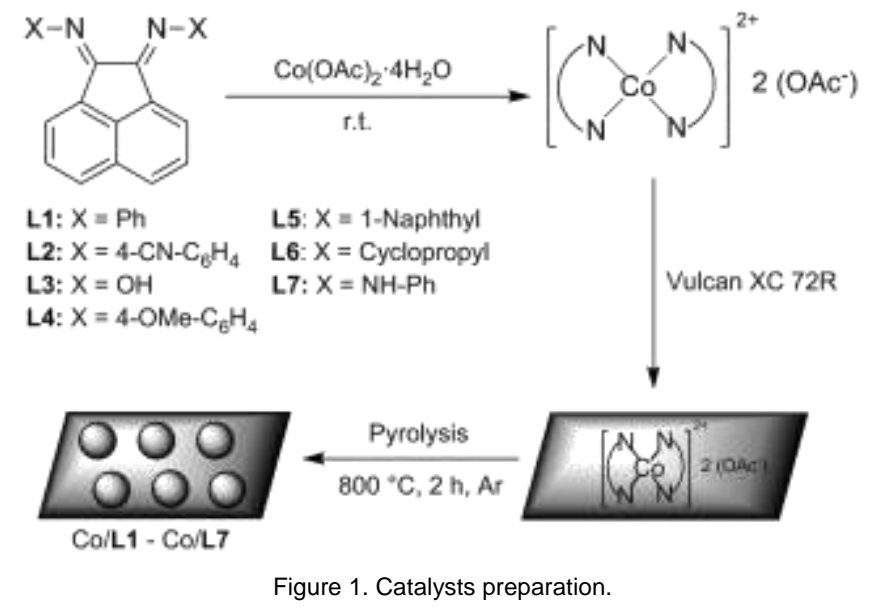

2.4. General methods for catalytic reactions in the autoclave

In an $8 \mathrm{~mL}$ glass vial fitted with a magnetic stirring bar and a septum cap, the catalyst (the amount depends of the catalyst) was added followed by the nitroarene $(0.5 \mathrm{mmol})$, the internal standard (hexadecane, $20 \mathrm{mg}$ ) and the solvent $(2 \mathrm{~mL}$ ). A needle was inserted in the septum cap, which allows dihydrogen to enter. The vials (up to 7) were placed into a $300 \mathrm{~mL}$ steel Parr autoclave which was flushed twice with dihydrogen at 20 bar and then pressurized to 50 bar. Then the autoclave was placed into an aluminum block pre-heated at $110^{\circ} \mathrm{C}$. At the end of the reaction, the autoclave was quickly cooled down at 
room temperature with an ice bath and vented. Finally, the samples were removed from the autoclave, diluted with a suitable solvent, filtered using a Pasteur pipette filled with Celite ${ }^{\circledR}(6 \mathrm{~cm}$ pad) and analyzed by GC using $n$-hexadecane as internal standard. Control experiments showed that the position of the vial inside the autoclave is not influential. The same outcome was obtained when the reaction was repeated by moving a vial from a peripheral to a central position.

\subsection{Procedure for quantitative determination of the reaction products}

All nitroarenes employed and all anilines reported in Figure 8 are commercially available compounds. Their amount was determined by GC analysis (HP 6890 series GC system) using $n$-hexadecane as internal standard and calibrating the response factor by using pure compounds (Aldrich, Alfa-Aesar, Tokyo Chemical Industry). For product 2aa, at the end of the reaction the catalyst was separated using a Pasteur pipette filled with Celite ${ }^{\circledR}$ and the Celite ${ }^{\circledast}$ pad was washed with EtOH. The solvent was evaporated and the desired product isolated using column chromatography (AcOEt:heptane $=1: 1$ ). The product was obtained as a light brown solid. Regarding product $\mathbf{2} \mathbf{a b}$, after the reaction was complete, the catalyst was separated using a Pasteur pipette filled with Celite ${ }^{\circledR}$ and the Celite ${ }^{\circledR}$ pad was washed with AcOEt. The solvent was removed in vacuo affording the product as a pale orange solid without the need of purification procedures. For the spectroscopic characterization of both the products see the Supporting Information.

\subsection{Procedure for recycling experiments}

For the catalyst recycling experiments, six-fold scaled up reactions were carried out. All the reactions were performed in glass vials set up according to previously described procedure. After completion of the reaction the content of the vial was quantitatively transferred into a centrifuge tube. Hereafter, the reaction mixture was centrifugated and the catalyst was separated from the supernatant. The catalyst was washed three times with $\mathrm{EtOH}$ and dried under vacuum overnight. This material was then used for the next catalytic reaction.

\subsection{Maitlis' hot filtration test}

The procedure for setting up a standard catalytic experiment was followed, but the reaction was interrupted after 2 hours. Hereafter, the autoclave was cooled down to room temperature and vented. A small amount of the vial content was filtered through a Pasteur pipette filled with Celite ${ }^{\circledR}(6 \mathrm{~cm}$ pad) and an aliquot of the filtrate was analyzed by GC. Then the remaining reaction mixture was quantitatively transferred into a Schlenk flask and heated up to $90{ }^{\circ} \mathrm{C}$ for $1 \mathrm{~h}$. The mixture was rapidly filtered while hot using a Pasteur pipette filled with Celite ${ }^{\circledast}(6 \mathrm{~cm}$ pad). The filtrate was quantitatively transferred into a clean reaction vial and subjected to the standard reaction conditions. In the latter case, the reaction time was prolonged to $24 \mathrm{~h}$ in order to take into account any soluble Co species that exhibit only low catalytic activity. The reaction mixture was eventually analyzed by GC.

\section{Results and discussion}

\subsection{Characterization of the catalytic materials}

Four catalytic materials (Co/L1, Co/L2, Co/L3 and Co/L7) were fully characterized by using X-ray diffraction (XRD), X-ray photoelectron spectroscopy (XPS), transmission electron microscopy (TEM) and temperature programmed reduction (TPR) techniques. We commenced the catalyst characterization with XRD measurements in order to identify the constituting phases of the sample (Figure 2). 


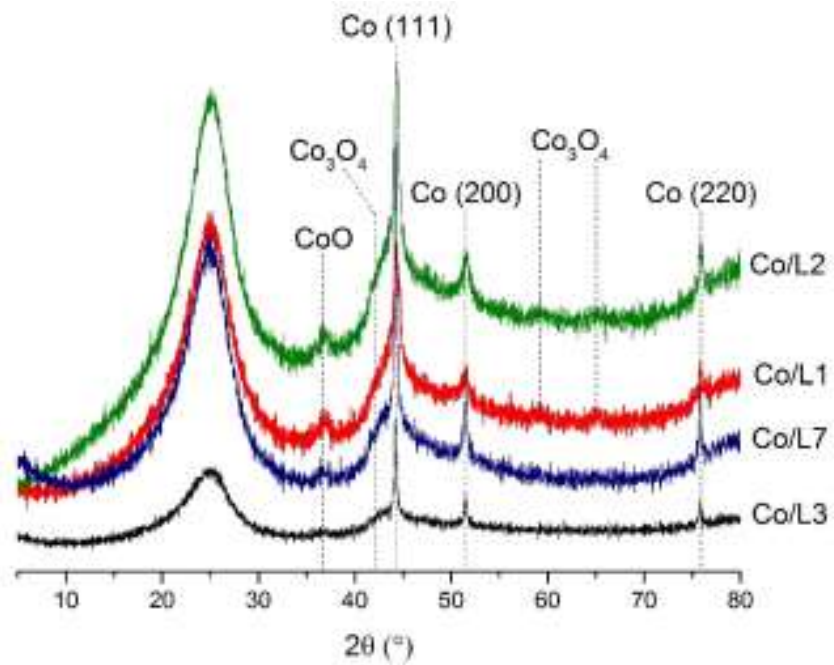

Figure 2. XRD patterns of the selected catalysts.

The XRD patterns revealed that the main species present is metallic Co. In fact, peaks at $2 \theta$ values of 44.4 , 54.7 and 76.0 corresponds to (111), (200) and (220) crystal planes of cobalt in its ground the zero oxidation state.[69] Minor peaks corresponding to $2 \theta$ values of $37.3,42.5,59.5$ and 65.2 were further detected and assigned to $\mathrm{CoO}$ and $\mathrm{Co}_{3} \mathrm{O}_{4}[70]$. In addition, the broad peak at around $2 \theta=25$ is ascribed to the amorphous carbon-based support.

Next, XPS was employed to investigate the surface composition of the materials. Figure 3 proves that nitrogen is incorporated into the carbonaceous matrix indicating that the employed ligands participate in the generation of these materials.
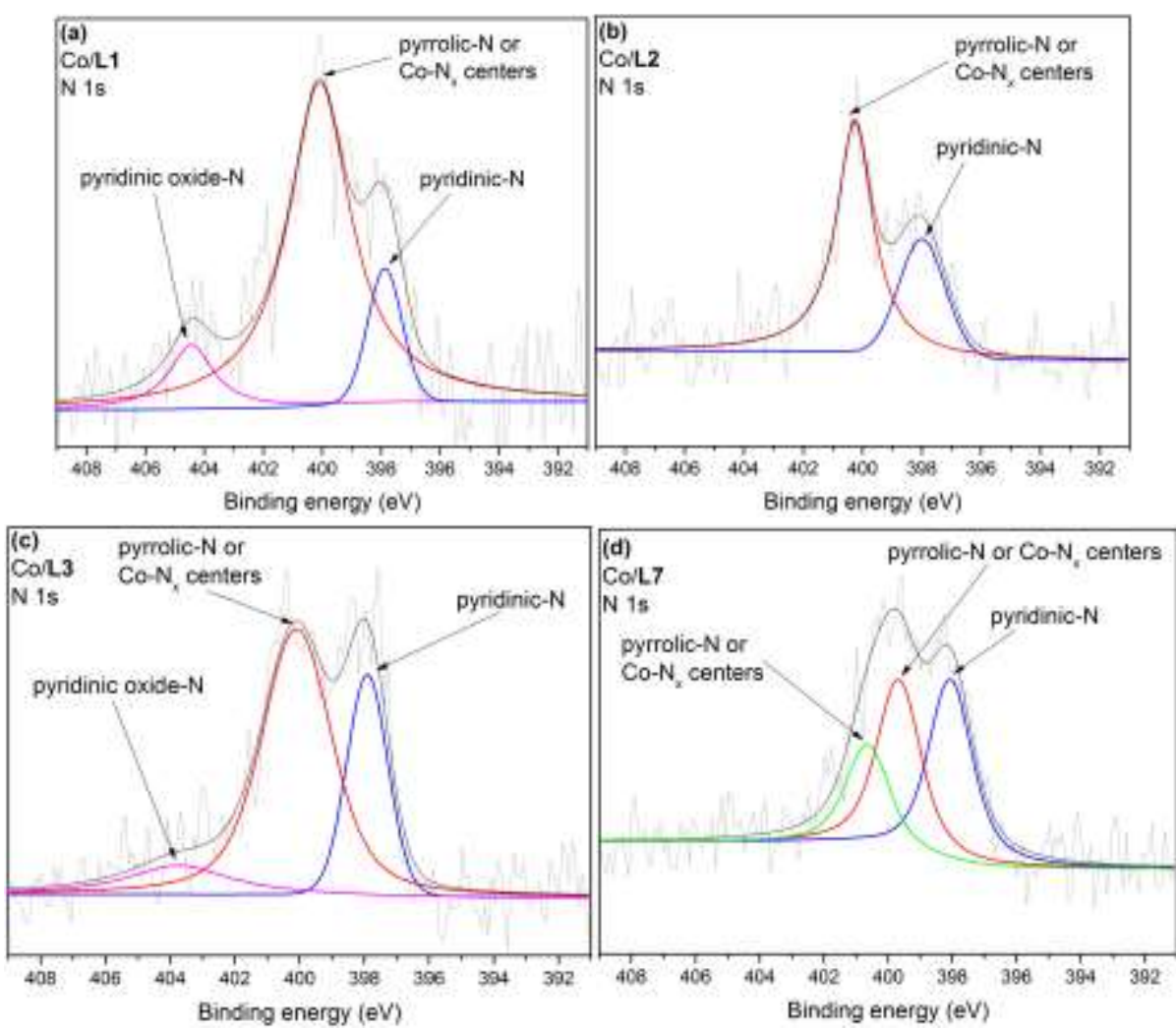

Figure 3. High-resolution N 1s spectra of Co/L1 (a), Co/L2 (b), Co/L3 (c) and Co/L7 (d). For XPS survey, O 1s, C 1s and Co 2p of the selected catalysts see SI (Figures S1, S2, S3, S4 and corresponding tables).

Deconvolution of the $\mathrm{N}$ 1s spectrum gives rise at least to two individual peaks for each catalyst. Detected peaks ranging from $397.9 \mathrm{eV}$ to $398.1 \mathrm{eV}$ are ascribed to pyridinic-type $\mathrm{N}$ atoms while peaks around $400 \mathrm{eV}$ 
can be ascribed to pyrrolic-type $\mathrm{N}$ atoms or to $\mathrm{N}$ coordinated to Co (Co- $\mathrm{N}_{\mathrm{x}}$ centers) [71]. Because of the expected proximity of the latter signals, it is impossible to unequivocally quantify the two independent contributions. Catalysts Co/L1 and Co/L3 exhibited two additional peaks at $404.4 \mathrm{eV}$ and $403.8 \mathrm{eV}$, respectively. These can be assigned to $\mathrm{N}$-oxides of the pyridinic $\mathrm{N}$ modifications. In the case of $\mathrm{Co} / \mathrm{L} \mathbf{3}, \mathrm{N}$ oxide formation upon pyrolysis is explained by the presence of oxygen directly bound to the chelating nitrogen atom in the precursor whereas in the thermally treated Co/L1 system the $\mathrm{N}-\mathrm{O}$ signals are likely to originate from traces of adventitious oxygen inside the pyrolysis oven. Co/L7 showed slightly different peak features with three states at $398.1 \mathrm{eV}, 399.7 \mathrm{eV}$ and $400.6 \mathrm{eV}$. Whereas the first state can be attributed to pyridinic $\mathrm{N}$ as for the other samples, the both latter ones can be correlated to the Co- $\mathrm{N}_{\mathrm{x}}$ centers and pyrrolic N. Co $2 p$ region was further examined (see Figures S1, S2, S3 and S4 in the Supporting Information). Catalysts Co/L1 and Co/L2 displayed similar peaks. For the Co/L1 and Co/L2 two peaks were observed, one at $780 \mathrm{eV}$ corresponding to the $2 \mathrm{p}_{3 / 2}$ state and the other one at $795 \mathrm{eV}$ correlated with the $2 \mathrm{p}_{1 / 2}$ state. Due to the low amount of $\mathrm{Co}$ it is not possible to distinguish between di- and trivalent Co. Peaks at $786 \mathrm{eV}$ and $800 \mathrm{eV}$ (typical for CoO) were found for the other two samples [26]. Finally, Co/L7 presented an additional peak at $778.8 \mathrm{eV}$ representative of Co atoms in zero oxidation state [72]. In addition, carbon and oxygen XPS regions were studied (see Supporting Information). Concerning the former, the four catalysts displayed an analogous pattern. The peaks at 283.8, 284.9 and 285.2-286.3 eV can be attributed to the presence of $\mathrm{C}=\mathrm{C}, \mathrm{C}=\mathrm{N}$ and $\mathrm{C}-\mathrm{N}$ bonds confirming the inclusion of the $\mathrm{N}$ atoms into the graphitic matrix [26]. Every $\mathrm{C} 1 \mathrm{~s}$ spectra showed the shake-up feature around $290 \mathrm{eV}$ arising from the $\pi$ to $\pi^{*}$ transition typical for graphitic like compounds. The interpretation of the oxygen region is not straightforward due to a multitude of possible $\mathrm{O}$ containing compounds, e.g. $\mathrm{CoO}, \mathrm{Co}(\mathrm{OH})_{2}$ and several organic compounds with $\mathrm{C}-\mathrm{O}$ and $\mathrm{C}=\mathrm{O}$ bounds. The peaks between 530.6 and $533 \mathrm{eV}$ can be ascribed to all these compounds [73].

To evaluate morphological differences caused by the use of different ligands, high resolution scanning transmission electron microscopy (STEM) technique was exploited. Parallel high angle annular dark field (HAADF) and annular bright field (ABF) images were taken. The HAADF images are sensitive to differences in the atomic number ( $Z$ ) of the atoms present in the sample. In the current case, oxidic cobalt phases show less contrast than metallic cobalt. In combination with EDX measurements and indexing of high resolution images, it is possible to describe the Co containing phase nature. Since HAADF prefers the imaging of heavy elements, $A B F$ has to be used for light elements like carbon. By using this technique, graphitic structures at the top of nanoparticles were observed. Figure 4 show typical images for catalysts Co/L1, Co/L2, Co/L3 and Co/L7. The different appearance of particles with metallic core and oxidic shells can be easily seen. Whereas Co/L1 contains completely covered particles, the oxidic coverage decreases for Co/L2 and Co/L3. Co/L7 shows a different morphology. Here, the Co-containing phase is split into agglomerates of small oxidic and bigger nearly uncovered metallic particles. As shown by the ABF images graphitic structures (graphene layers) appear at the top of metallic Co fractions intimately in contact with the particles. For Co/L1 no graphitic envelops were found since the metallic cobalt is completely embedded by cobalt oxide. From Co/L2 to $\mathbf{C o} / \mathbf{L} \mathbf{7}$ the cobalt oxidic shell decreases and it can be observed (Co/L2) that only free metallic Co is in tight contact to the graphitic or graphene layers. 

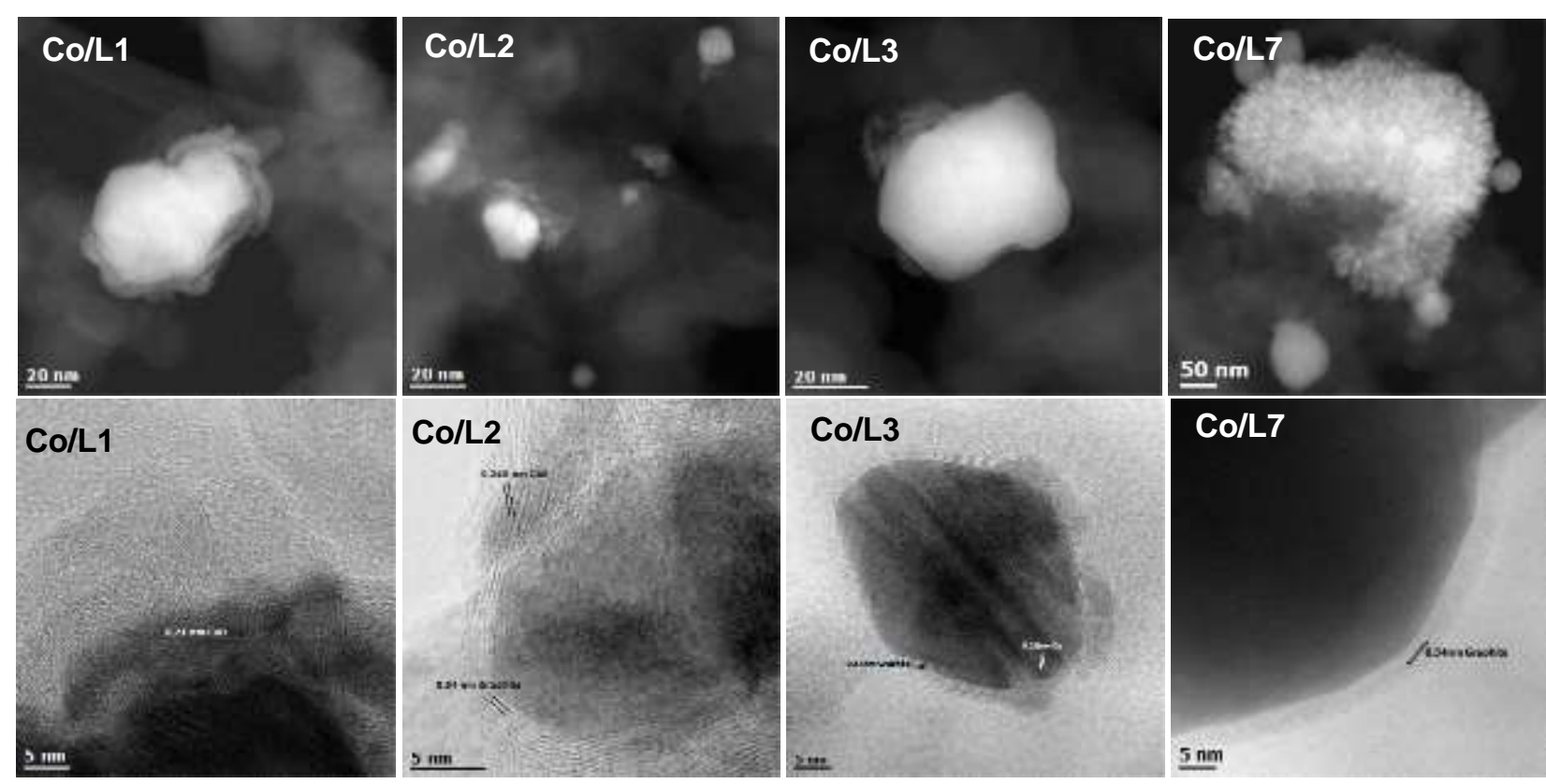

\section{Co/L2}

Co/L3

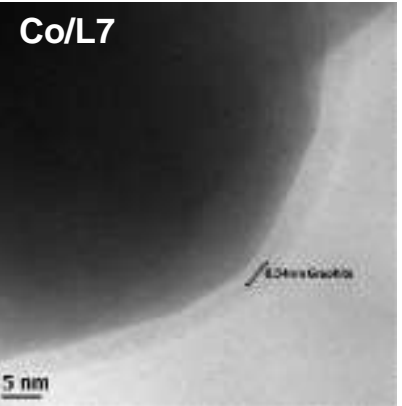

Figure 4. STEM images of the selected catalysts. HAADF and ABF images are depicted in the upper and lower row, respectively. For supplementary STEM images and EDX patterns see SI (from Figure S5 to Figure S14).

Finally, TPR measurements were performed to get insight into the reducibility of the catalytic materials. As shown in Figure 5, Co/L1, Co/L2 and Co/L3 showed a very similar behavior. In contrast, Co/L7 displayed a peak area much smaller than the previous ones. This is ascribed to a greater metallic contribution in the NP spot. This result is in agreement with that obtained from the XPS and STEM studies for the same catalysts.

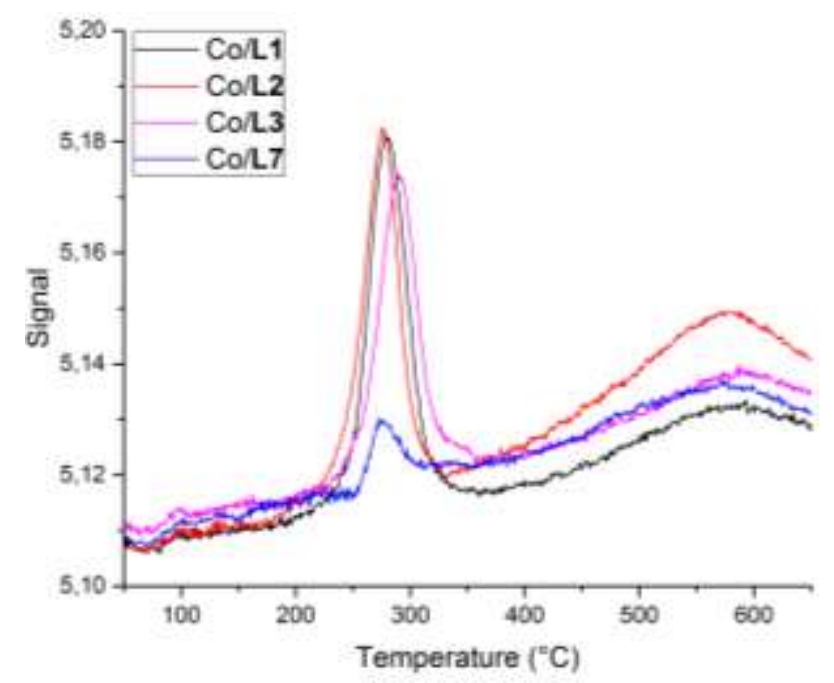

Figure 5. TPR of selected catalysts.

In conclusion, most of the prepared materials exhibit a core-shell structure [74] in which metallic and oxidic species ( $\mathrm{COO}$ ) coexist. In addition, nitrogen-doped graphitic and graphene-type layers in contact with these NP are observed.

\subsection{Evaluation of the catalytic performances}

The catalytic performance of the prepared materials was primarily explored in the hydrogenation of nitrobenzene to aniline. Aniline and its derivatives are key intermediates for the pharmaceutical, agrochemical and dye industries [75]. In the last century, classic stoichiometric manufacturing processes 
(e.g. Béchamp reduction or sulfur-based reduction reactions) were replaced by more economical catalytic protocols [76, 77]. Although the hydrogenation of simple substituted nitro compounds does not pose significant selectivity problems, the situation is more challenging for substrates carrying reducible or poisoning-capable functional groups [78]. Therefore, the development of efficient, robust, cheap and green catalysts for the selective reduction of nitro compounds continues to attract the attention of academic and industrial researchers. Initially, Co/L1 was employed for the hydrogenation of nitrobenzene in the presence of different solvents. While apolar solvents proved to be detrimental for the reactivity, polar ones allowed for higher conversions (Table S6). In particular, EtOH was found to be the best solvent. The addition of a small amount of water (1:20 by volume) further increased nitrobenzene conversion. We were pleased to obtain complete selectivity towards the desired aniline (Figure S15). In agreement with previous findings, organic bases are beneficial for achieving higher conversions [79]. Thus, different base additives were tested (Table S7) in combination with catalyst Co/L2. Inorganic bases led to full conversion but the selectivity into the desired aniline dropped owing to the formation of azobenzene and azoxybenzene as side products. On the contrary, when $\mathrm{Et}_{3} \mathrm{~N}$ was employed, complete conversion and full selectivity were achieved, thus avoiding the formation of undesired side products. For a complete investigation of the catalytic system, acidic additives were also tested (Table S8). Two Brønsted ( $\mathrm{HBF}_{4}$ and $\mathrm{CF}_{3} \mathrm{COOH}$ ) and two Lewis acids $\left(\mathrm{Al}(\mathrm{OTf})_{3}\right.$ and $\mathrm{Zn}(\mathrm{OTf})_{2}$ ) were used at various concentrations. In all cases a slight decrease of the conversion and a drop in the selectivity were detected. The decline of the selectivity is attributed to the formation of 2-ethoxy- and 4-ethoxyaniline. Control experiments carried out under a nitrogen atmosphere without the catalyst and in the presence of $\mathrm{HBF}_{4}$ (2 equivalents) revealed that nitrobenzene, nitrosobenzene or aniline do not react. On the contrary, $\mathrm{N}$-phenylhydroxylamine under the same reaction conditions led to the formation of 2-ethoxyaniline, 4-ethoxyaniline and azoxybenzene in 49, 9, and $29 \%$ yield, respectively. This behavior was previously reported in the case of both Brønsted [80,81] or Lewis [82] acids. Having good conditions in our hands, the seven prepared catalysts were tested in the benchmark hydrogenation of nitrobenzene to aniline with and without the addition of $\mathrm{Et}_{3} \mathrm{~N}$ (Figure 6).
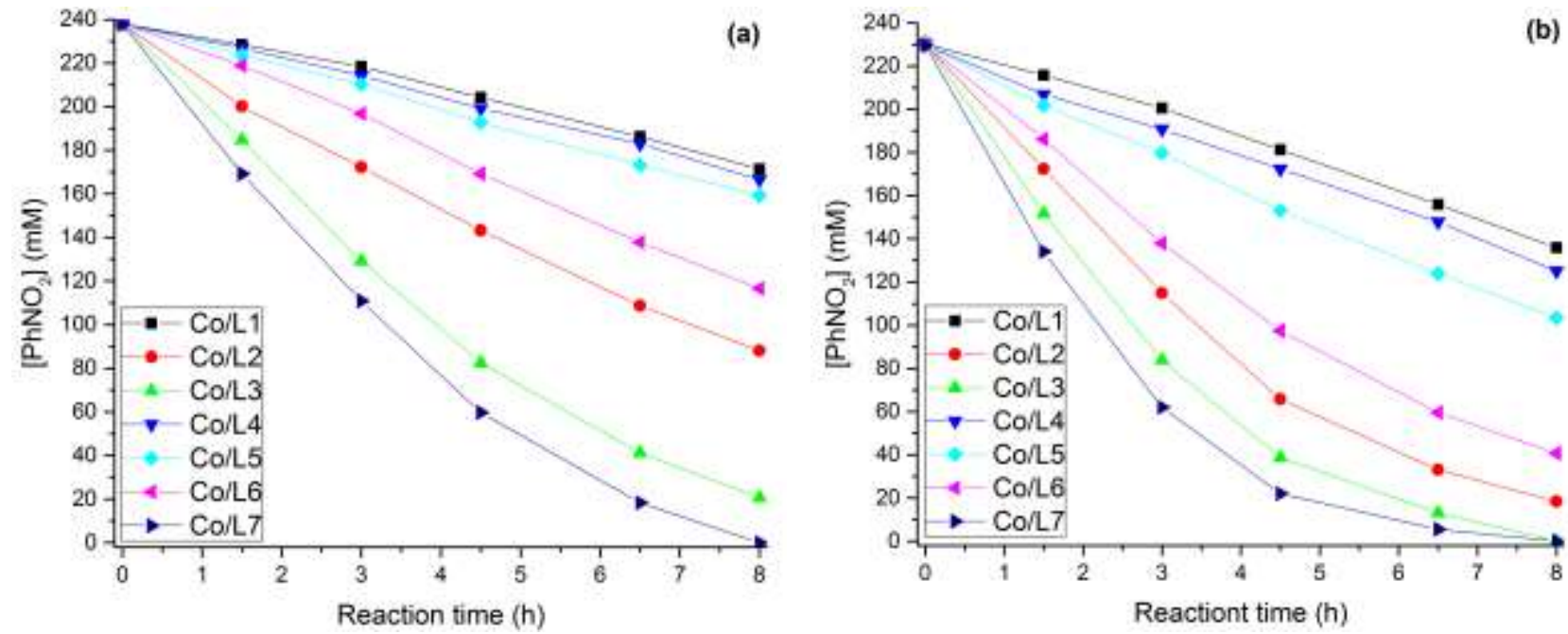

Figure 6. Variation of $\left[\mathrm{PhNO}_{2}\right]$ during the reaction without (a) and with (b) 1 equiv. of $\mathrm{Et}_{3} \mathrm{~N}$. Reaction conditions: $0.5 \mathrm{mmol} \mathrm{PhNO}$, $0.7 \mathrm{~mol} \% \mathrm{Co}$, solvent: 2 $\mathrm{mLEtOH}+100 \mu \mathrm{L} \mathrm{H} \mathrm{H}_{2} \mathrm{O}, 50$ bar $\mathrm{H}_{2}, 110^{\circ} \mathrm{C}$.

More specifically, Co/L7 displayed the maximum activity followed by Co/L3, Co/L2, Co/L6, Co/L5, Co/L4 and finally $\mathrm{Co} / \mathbf{L 1}$. Interestingly, this trend is retained even if $\mathrm{Et}_{3} \mathrm{~N}$ was added, which indicates that the base acts as promoter but leaves the catalytic material unaffected. In all cases selectivities were very high (Figure $\mathrm{S} 15 \mathrm{~b}$ and $\mathrm{d}$ ) and no side-products such as nitrosobenzene, azobenzene or azoxybenzene were detected at the end of the catalytic experiments. This observation, coupled with the fact that selectivities into aniline 
increased with increasing reaction time, clearly demonstrates that phenylhydroxylamine is an intermediate in the present catalytic transformation.

Next, the reuse of Co/L7 was investigated in a six-fold scaled up reaction showing a good recyclability (Figure 7).

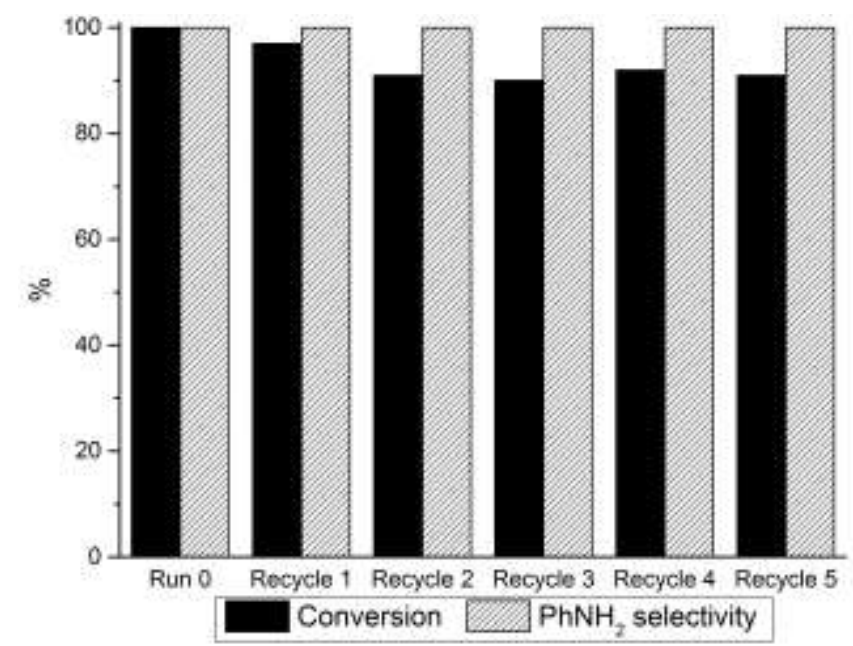

Figure 7. Recycling experiments of $\mathrm{Co} / \mathrm{L} 7$. Reaction conditions: $3 \mathrm{mmol} \mathrm{PhNO} 2,0.7 \mathrm{~mol} \% \mathrm{Co}$, solvent: $12 \mathrm{~mL} \mathrm{EtOH}+600 \mu \mathrm{L} \mathrm{H} 2 \mathrm{O}, 8 \mathrm{~h}, 50$ bar $\mathrm{H}_{2}, 110{ }^{\circ} \mathrm{C}$

A slight decrease of the conversion was observed after the first and second recycling. However, after the second run the catalytic performance remained constant. In addition, the selectivity was completely retained at a value of $>99 \%$ throughout the 5 recycling experiments. ICP analysis of the liquid phase after each recycle indicated no leaching of Co (detection limit $0.5 \mathrm{ppm}$ ). In addition, Maitlis' hot filtration test was carried out in order to detect whether soluble active Co species were present to catalyse the reaction, (Table S10). The results confirmed that no active cobalt was leached. Thus, we conclude that the employed catalyst is inherently heterogeneous.

Subsequently, the reaction scope was explored employing various substituted aromatic nitro compounds as substrates (Figure 8). 


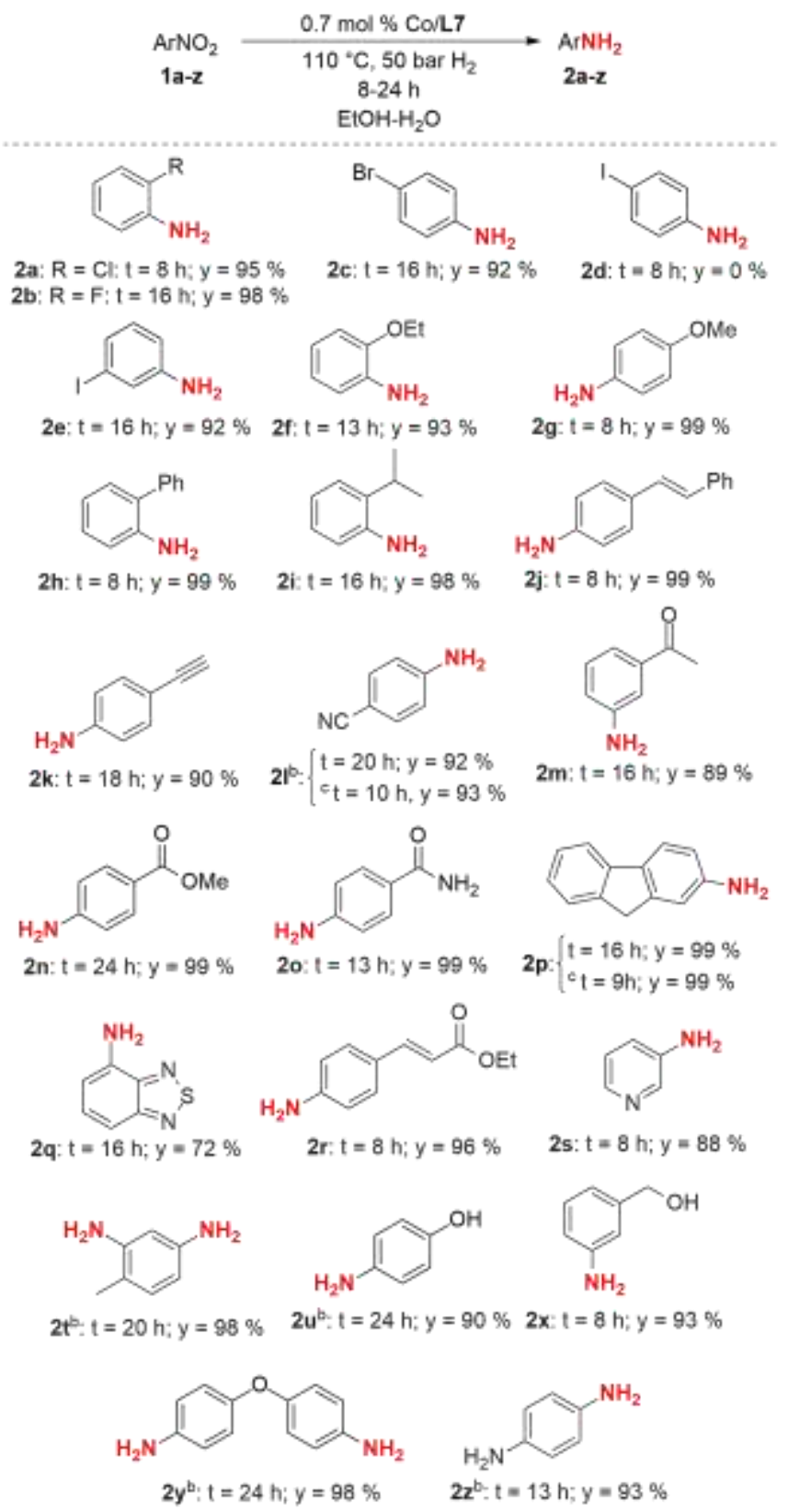

Figure 8. Hydrogenation of nitroarenes: substrate scope. Reaction conditions: $0.5 \mathrm{mmol}$ nitroarene, $2 \mathrm{~mL} \mathrm{EtOH}+100 \mu \mathrm{L} \mathrm{H} \mathrm{H}_{2} \mathrm{O}$ Complete conversions were observed. GC yields using $n$-hexadecane as internal standard; ${ }^{b} 1.4 \mathrm{~mol} \%$ of $\mathrm{Co} / \mathrm{L} 7$ was used; ${ }^{c} 1$ equiv. (with respect to the substrate) of Et $3 \mathrm{~N}$ was added.

The catalytic system is excellently tolerant to halogen containing substrates. The presence of $\mathrm{Br}, \mathrm{Cl}$ or $\mathrm{F}$ did not affect the selectivity and the various nitro compounds were smoothly converted into corresponding anilines (2a, $\mathbf{2} \mathbf{b}$ and $\mathbf{2} \mathbf{c}$ ). Only in the case of 4-iodonitrobenzene (1d), dehalogenation occurred producing aniline and $\mathrm{N}$-ethylaniline in $87 \%$ and $13 \%$ yield, respectively. The formation of $\mathrm{N}$-ethylaniline is likely to be caused by in situ formation of Etl from ethanol (solvent) and HI derived from the dehalogenation followed by alkylation of the amino group [83]. Notably, 3-iodonitrobenzene (1e), did not show this undesired pathway affording the desired product in excellent yield. Electron donating substituents $(\mathbf{2 f}, \mathbf{2 g}, \mathbf{2 u}, \mathbf{2 x}, \mathbf{2 y}$, $\mathbf{2 z}$ ) and steric hindrance $(\mathbf{2} \mathbf{h}, \mathbf{2} \mathbf{i})$ were well tolerated. Other reduction-labile functional groups such as

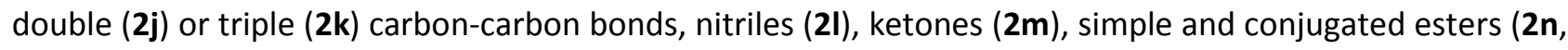
$\mathbf{2 r}$ ) and amides (20) are well tolerated affording the corresponding anilines in very high yields. Heteroaromatic nitro compounds were hydrogenated furnishing the corresponding anilines in good (2s) and moderate (2q) yields. An excellent selectivity was also achieved in the reduction of 2,4-dinitrotoluene (1t) into the corresponding diamine. Such hydrogenation is currently employed yearly on a multi-million 
tons scale as a step in the preparation of 2,4-toluendiisocyanate [4]. As mentioned earlier, the addition of 1 equivalent of $\mathrm{Et}_{3} \mathrm{~N}$ boosts the activity of the catalytic system (see $\mathbf{1 l}$ and $\mathbf{1 q}$ ). The pharmaceutically important substrates nitroresorcinol (1aa) and Flutamide (1ab) were also investigated in the catalytic hydrogenation (Figure 9). The corresponding reduction products are key-intermediates in the preparation of biologically active compounds and are valuable starting molecules in total syntheses [84-90].
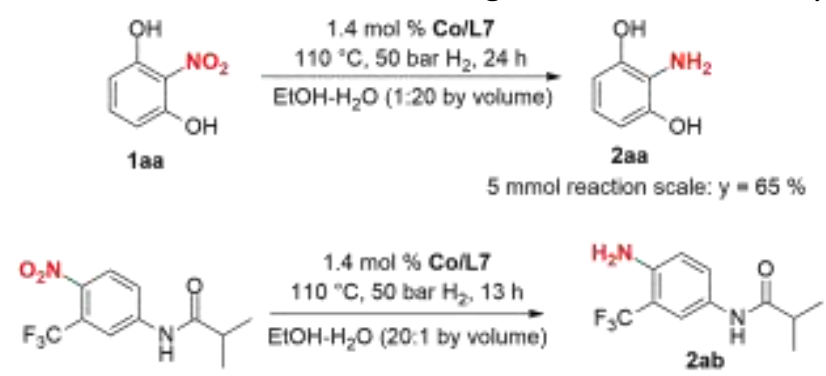

$1 \mathrm{ab}$ (Flutamide)

5 mmol reaction scale: $y=93 \%$

Figure 9. Co/L7 catalysed synthesis of biologically important molecules. Yields refer to isolated compounds.

In the case of 1aa, the reaction was slow using $\mathrm{EtOH}-\mathrm{H}_{2} \mathrm{O} 20: 1$ as solvent mixture but proceeded faster in a reaction media almost exclusively composed of water. This is likely to be attributed to the very strong intramolecular $\mathrm{H}$-bond between the partially positively charged $\mathrm{H}$ of the $\mathrm{OH}$ groups and the two negativelycharged oxygen atoms of the adjacent nitro group [91]. However, it was not possible to conduct the catalytic transformation in pure water as the solubility of the substrate was insufficient in this case. This reaction is the first example of a non-noble metal catalysed reduction of 2-nitroresorcinol to 2aminoresorcinol. Similarly, hydrogenation of $1 \mathbf{a b}$ proceeded with excellent chemoselectivity and its purification does not require expensive and waste-producing chromatographic separation techniques. In fact, just filtration over Celite ${ }^{\circledR}$ and consecutive solvent evaporation were needed to obtain the product in a pure form at the end of the reaction.

\subsection{Kinetic studies}

In order to understand the different catalytic behavior of the seven employed catalysts, kinetic experiments were carried out. The collected data, summarized in Figure 10, are in accordance with a first order kinetics in $\mathrm{PhNO}_{2}$.
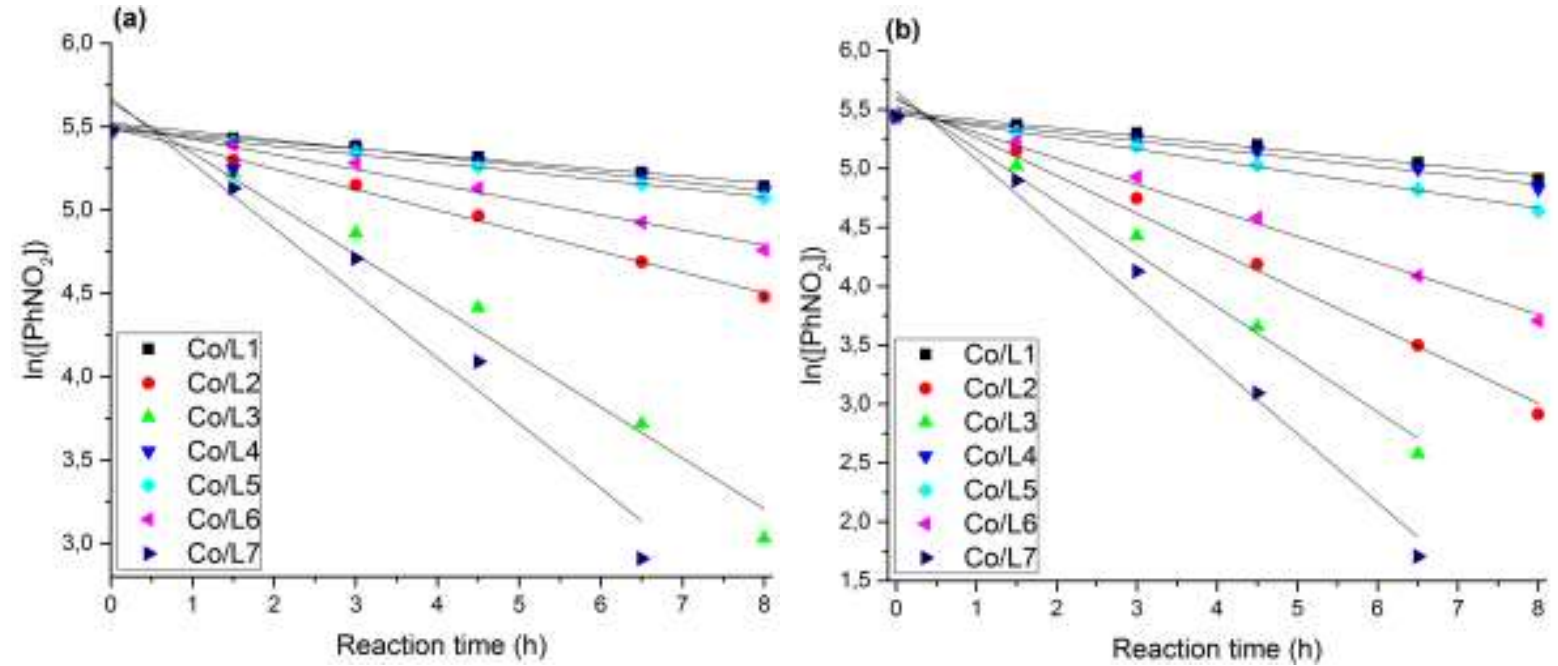

Figure 10. First order kinetic plot of the seven catalysts without (a) and with (b) 1 equiv. of Et 3 N. Reaction conditions are reported in the caption of Figure 6.

Despite the structural and morphological similarity of the prepared materials, the bulk $\mathrm{N}$ content (wt. \%) varies from catalyst to catalyst (see Table S1). Since control experiments confirmed that the catalyst 
prepared in the absence of the nitrogen ligand is totally inactive (Table S11, entry 5), we assumed that the activities of the catalysts correlates with the bulk nitrogen content in the final catalytic material. In fact, plotting the kinetic constant vs the total nitrogen content in the catalytic material, a clear trend is observed (Figure 11): the higher the nitrogen content, the better the activity of the catalyst. The same trend is retained if the reactions were carried out in the presence of 1 equivalent of $\mathrm{Et}_{3} \mathrm{~N}$ (see also Figure S16). In this case, kinetic constants were dramatically improved (Table S9).

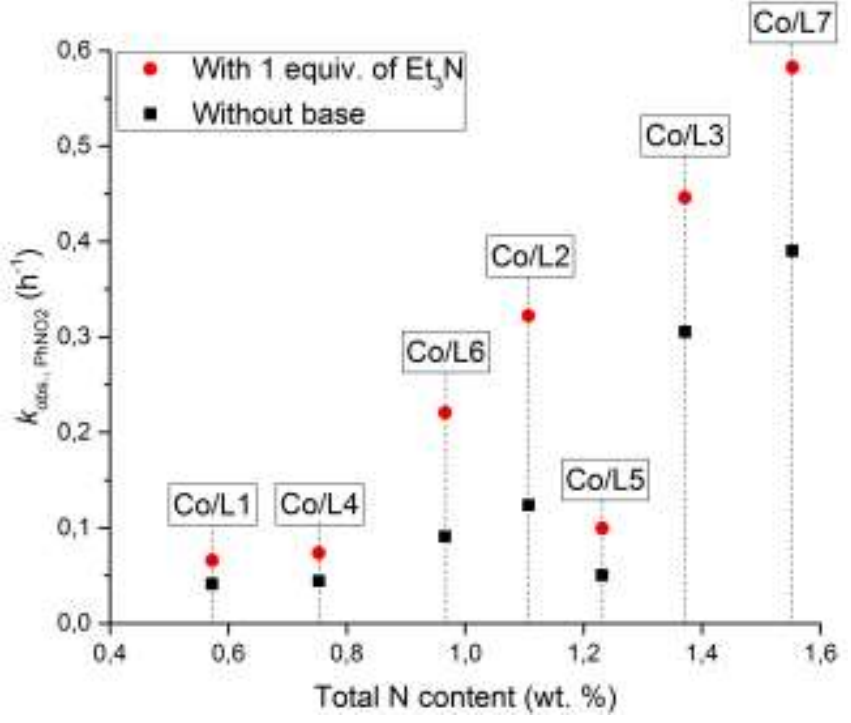

Figure 11. Correlation between first-order kinetic constant and total nitrogen content in the catalyst material.

This general trend is observed for all catalysts except for Co/L5. This can be attributed to the steric hindrance of the naphthyl groups that probably negatively affect the coordination ability of the ligand to the metal center. Thus, the $\mathrm{N}$ atoms are equally incorporated into the carbon matrix but not close to the catalytically active site. In fact, the catalyst prepared using a 1:1 molar ratio of Co(OAc) $)_{2}$ and $\mathbf{L} 5$ exhibited a similar activity to Co/L5. Conversely, the catalyst prepared by combining $\mathrm{Co}(\mathrm{OAc})_{2}$ and L1 (less sterically hindered) in a 1:1 molar ratio showed a much lower activity (Figure S19). In addition, for the selected characterized materials, a correlation with the free pyridinic $\mathrm{N}$ content measured by XPS was established (Figure 12 and Figure S17).

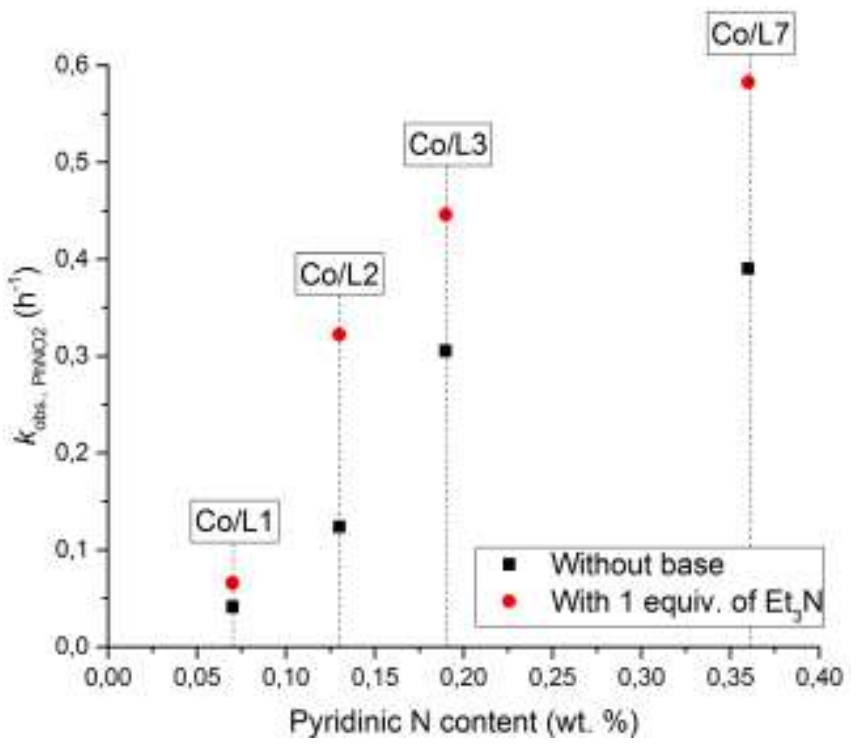

Figure 12. Correlation between first order kinetic constant and free pyridinic $\mathrm{N}$ content in the final material 
Since no similar correlations were observed in the case of pyrrolic/Co- $\mathrm{N}_{\mathrm{x}}$ configurations (Figure S18), we conclude that uncoordinated pyridinic $\mathrm{N}$ atoms play a pivotal role in the catalytic activity (graphitic or $\mathrm{N}$ oxidic configurations were not taken into account since they were not found in all the catalysts). A related observation has been described for NGr-based catalysts for electrochemical applications [24, 92-94]. However, to the best of our knowledge, this is the first time that such a correlation is described for catalytic hydrostions of investigations of the reaction order with respect to $\mathrm{Et}_{3} \mathrm{~N}$ and hydrogen pressure using Co/L2 as the model catalyst indicate a first-order kinetics in $\mathrm{Et}_{3} \mathrm{~N}$ and $\mathrm{H}_{2}$ (Figures 13 and 14).

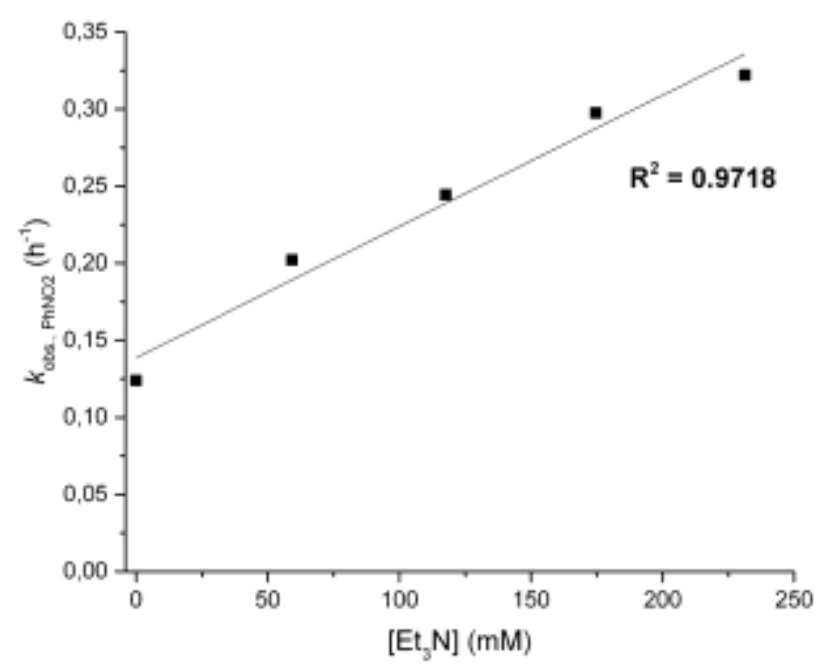

Figure 13. First order kinetic plot for $\mathrm{Et}_{3} \mathrm{~N}$ (Co/L2 as catalyst).

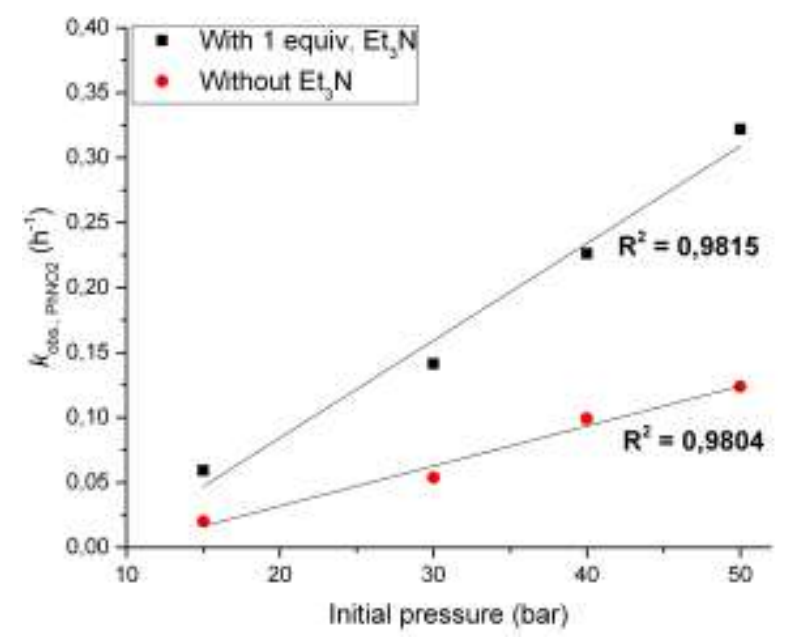

Figure 14. First order kinetic plot for hydrogen pressure (Co/L2 as catalyst).

This latter observation is ascribed to the linear dependence of the $\mathrm{H}_{2}$-solubility with increasing gas pressure in alcoholic solvents [95-97]. First order kinetics with respect to nitrobenzene, dihydrogen and, if present, triethylamine cannot be explained by a single slow step without the existence of at least one kinetically relevant equilibrium stage before the r.d.s. Given that activation of nitrobenzene is very unlikely to be reversible (nitroarenes are among the very poor ligands and their metal complexes are extremely labile), the most likely explanation for the observed kinetic data is that reversible formation of an activated form of dihydrogen first occurs, the equilibrium being strongly shifted to the reagents side (if this were not true the kinetics would deviate from first order for both $\mathrm{H}_{2}$ and $\mathrm{Et}_{3} \mathrm{~N}$. See the Supporting 
Information for a detailed discussion). The activated dihydrogen then reacts in the r.d.s. with nitrobenzene. Based on reactivity data, we postulate that this kind of hydrogenations proceeds by a heterolytic activation of dihydrogen [98-10095-97]. The kinetic data obtained in this work not only confirms the general validity of this explanation for this class of catalysts, but also add further. In particular, the linear dependence of the reaction rate on triethylamine concentration with a non-zero intercept points to a reaction scenario where two independent and competing mechanisms occur, in which either a nitrogen atom of the support or that of $\mathrm{Et}_{3} \mathrm{~N}$ is involved, but not both. Based on the kinetic investigations, we propose the pyridinic $\mathrm{N}$ content is crucial for the catalyst activity. The fact that the dihydrogen activation equilibrium is shifted towards the left is not only consistent with the kinetic orders observed, but also explains why the rate of the $\mathrm{Et}_{3} \mathrm{~N}$-free reaction is not affected by triethylamine concentration. Indeed, at any given moment the active sites are virtually all available independent of the $\mathrm{Et}_{3} \mathrm{~N}$ concentration. A schematic representation of the initial steps of the reaction is shown in Scheme 1.

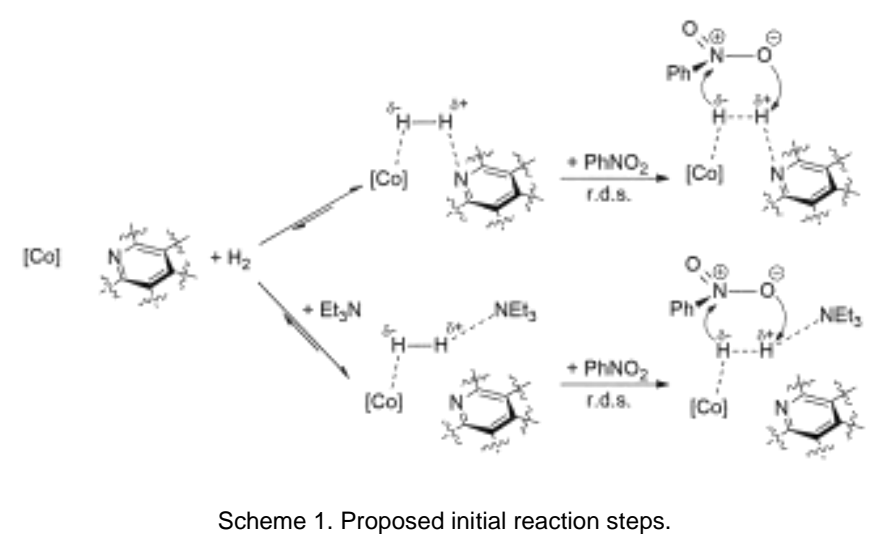

Recent both experimental [25, 45, 101-10498-101] and theoretical [105102] works dealing with transition metal/NGr catalysts indicate that the nature of the active sites can be a M- $\mathrm{N}_{\mathrm{x}}-\mathrm{Cy}$ network in which the metal is present as a single atom (single site heterogeneous catalyst). According to our structural characterization we postulate the involvement of either single-site Co centers or Co NP coordinated to pyridinic $\mathrm{N}$ atoms whose configurations are not definitely elucidated. The established correlation between non-coordinated pyridinic $\mathrm{N}$ configurations and activity (Figure 10) suggests an internal base role by the latter. The relationship between activity and amount of pyridinic $\mathrm{N}$ can be ascribed to its basicity. In agreement with this proposal, a recent study described that in NGr-based materials, the pyridinic $\mathrm{N}$ exhibits the maximum basicity among the three types of $N$ (the other two are pyrrolic and graphitic) [106103]. These conclusions are corroborated by control experiments. Indeed, it must be stressed that the contemporary presence of both a cobalt source and a nitrogen ligand before the pyrolysis step is required to obtain active catalysts. The materials prepared either without the addition of the $\mathrm{N}$-ligand or the metal (Table S11, entries 6-8) were inactive, whether $\mathrm{Et}_{3} \mathrm{~N}$ was also present or not [107104].

Finally, the most active catalyst (Co/L7) was compared with commercially available noble-metal based heterogeneous catalysts (Tables S13 and S14). Two model substrates were employed for that purpose: $(E)$ 4-nitrostilbene (1j) and 3-nitroacetophenone $(\mathbf{1} \mathbf{m})$. In both cases, Co/L7 showed superior chemoselectivity towards the formation of the desired products, while several side- and over-reduction products were detected when the reactions were carried out with standard noble-metal based catalysts.

\section{Conclusions}

In conclusion, an array of Co-based core-shell NGr decorated carbon-supported catalysts was prepared from the pyrolysis of well-defined Ar-BIAN and $\alpha$-diimine Co complexes. The catalytically active materials 
were successfully applied to the reduction of nitrobenzene to aniline using molecular hydrogen as the reductant. Furthermore, excellent chemoselectivities were achieved employing these catalysts in the hydrogenation of nitro compounds bearing reduction-labile functional groups. Straightforward kinetic measurements suggest a direct and linear correlation between the intrinsic activity of the catalysts (in terms of the kinetic constant) and the total amount of nitrogen in the support. An additional correlation between the activity and the pyridinic nitrogen content in the support was further demonstrated. For all employed catalysts, a dramatic increase in the activity (up to almost three times) was observed when an organic base was added to the reaction mixture. All our findings are in accordance with a polar reaction mechanism in which a heterolytic activation of the hydrogen molecule occurs.

We believe that the findings in this paper constitute a valuable source of inspiration for the design of new high performance materials that enable the hydrogenation of challenging substrates such as carboxylic acids and amides.

\section{Acknowledgments}

The work was supported by the state of Mecklenburg-Vorpommern (Germany), Ministero dell'Università e della Ricerca (MIUR, Italy, PRIN 2015_20154X9ATP) and F. Hoffmann-La Roche. The authors thank Mrs. Astrid Lehmann and Mrs. Anja Simmula (Analytic Department, LIKAT) for excellent technical assistance. Special thank is due to Dr. Hanan Atia (LIKAT) for theoretical and technical assistance regarding the TPR measurements. D.F. and F.F. thank Erasmus+ Programme and Milan University for a fellowship, respectively. 


\section{References}

[1] R.A. Sheldon, I. Arendes, U. Hanefeld, Green Chemistry and Catalysis, Wiley-VCH Verlag, 2007.

[2] C. Descorme, P. Gallezot, C. Geantet, C. George, ChemCatChem, 4 (2012) 1897-1906.

[3] M. Beller, A. Renken, R.A. Van Santen, Catalysis: From Principles to Applications, Wiley VCH-Verlag, 2012.

[4] H.-J. Arpe, Industrial Organic Chemistry, Wiley-VCH, 2010.

[5] J. Hagen, Industrial Catalysis: A Practical Approach, Wiley-VCH Verlag, 2015.

[6] M.L.C.M. Henckens, P.P.J. Driessen, E. Worrell, Resour. Conserv. Recy., 93 (2014) 1-8.

[7] R.M. Bullock, Catalysis without precious metals, Wiley-VCH Verlag, 2010.

[8] M.S. Holzwarth, B. Plietker, ChemCatChem, 5 (2013) 1650-1679.

[9] J.-P.D. Zhongwei Chen, Jiujun Zhang, Non-Noble Metal Fuel Cell Catalysts, Wiley-VCH, 2014.

[10] B. Su, Z.-C. Cao, Z.-J. Shi, Acc. Chem. Res., 48 (2015) 886-896.

[11] K.H. Wedepohl, The Composition of Earth's Upper Crust, Natural Cycles of Elements, Natural Resources in: Elements and Their Compounds in the Environment, Wiley-VCH Verlag GmbH, 2008, pp. 2-16.

[12] A. Schaetz, M. Zeltner, W.J. Stark, ACS Catal., 2 (2012) 1267-1284.

[13] B.F. Machado, P. Serp, Catal. Sci. Technol., 2 (2012) 54-75.

[14] J. Albero, H. Garcia, J. Mol. Catal. A: Chem., 408 (2015) 296-309.

[15] R. Zhou, M. Jaroniec, S.-Z. Qiao, ChemCatChem, 7 (2015) 3808-3817.

[16] C.N.R. Rao, K. Gopalakrishnan, A. Govindaraj, Nano Today, 9 (2014) 324-343.

[17] X. Fan, G. Zhang, F. Zhang, Chem. Soc. Rev., 44 (2015) 3023-3035.

[18] S.R. Stoyanov, A.V. Titov, P. Král, Coord. Chem. Rev., 253 (2009) 2852-2871.

[19] H. Liu, Y. Liu, D. Zhu, J. Mater. Chem., 21 (2011) 3335-3345.

[20] H. Wang, T. Maiyalagan, X. Wang, ACS Catal., 2 (2012) 781-794.

[21] J. Masa, W. Xia, M. Muhler, W. Schuhmann, Angew. Chem. Int. Ed., 54 (2015) 10102-10120.

[22] L. He, F. Weniger, H. Neumann, M. Beller, Angew. Chem. Int. Ed., 55 (2016) 12582-12594.

[23] Q. Lai, Q. Gao, Q. Su, Y. Liang, Y. Wang, Z. Yang, Nanoscale, 7 (2015) 14707-14714.

[24] F. Jaouen, S. Marcotte, J.-P. Dodelet, G. Lindbergh, J. Phys. Chem. B, 107 (2003) 1376-1386.

[25] J. Han, Y.J. Sa, Y. Shim, M. Choi, N. Park, S.H. Joo, S. Park, Angew. Chem. Int. Ed., 54 (2015) 12622-12626.

[26] Y. Su, Y. Zhu, H. Jiang, J. Shen, X. Yang, W. Zou, J. Chen, C. Li, Nanoscale, 6 (2014) 15080-15089.

[27] H.-W. Liang, S. Bruller, R. Dong, J. Zhang, X. Feng, K. Mullen, Nat. Commun., 6 (2015).

[28] C.H. Choi, C. Baldizzone, J.-P. Grote, A.K. Schuppert, F. Jaouen, K.J.J. Mayrhofer, Angew. Chem. Int. Ed., (2015) n/a-n/a.

[29] D. Chauhan, P. Kumar, C. Joshi, N. Labhsetwar, S.K. Ganguly, S.L. Jain, New J. Chem., 39 (2015) 6193-6200.

[30] J. Xi, Y. Xia, Y. Xu, J. Xiao, S. Wang, Chem. Commun., 51 (2015) 10479-10482.

[31] C.E. Chan-Thaw, A. Villa, P. Katekomol, D. Su, A. Thomas, L. Prati, Nano Lett., 10 (2010) 537-541.

[32] X. Ning, H. Yu, F. Peng, H. Wang, J. Catal., 325 (2015) 136-144.

[33] J. Deng, H.-J. Song, M.-S. Cui, Y.-P. Du, Y. Fu, ChemSusChem, 7 (2014) 3334-3340.

[34] Y. Chen, L. Fu, Z. Liu, Chem. Commun., 51 (2015) 16637-16640.

[35] Y. Chen, S. Zhao, Z. Liu, PCCP, 17 (2015) 14012-14020.

[36] A.V. losub, S.S. Stahl, Org. Lett., 17 (2015) 4404-4407.

[37] C. Bai, A. Li, X. Yao, H. Liu, Y. Li, Green Chem., 18 (2016) 1061-1069.

[38] C. Yang, L. Fu, R. Zhu, Z. Liu, PCCP, 18 (2016) 4635-4642.

[39] S. Sahin, P. Mäki-Arvela, J.-P. Tessonnier, A. Villa, S. Reiche, S. Wrabetz, D. Su, R. Schlögl, T. Salmi, D.Y. Murzin, Appl. Catal., A, 408 (2011) 137147.

[40] P. Chen, F. Yang, A. Kostka, W. Xia, ACS Catal., 4 (2014) 1478-1486.

[41] J. Long, Y. Zhou, Y. Li, Chem. Commun., 51 (2015) 2331-2334.

[42] Z. Wei, J. Wang, S. Mao, D. Su, H. Jin, Y. Wang, F. Xu, H. Li, Y. Wang, ACS Catal., 5 (2015) 4783-4789.

[43] Z. Li, J. Li, J. Liu, Z. Zhao, C. Xia, F. Li, ChemCatChem, 6 (2014) 1333-1339.

[44] Y. Marco, L. Roldán, S. Armenise, E. García-Bordejé, ChemCatChem, 5 (2013) 3829-3834.

[45] L. Zhang, A. Wang, W. Wang, Y. Huang, X. Liu, S. Miao, J. Liu, T. Zhang, ACS Catal., (2015) 6563-6572.

[46] D. Li, D. Shi, Z. Chen, H. Liu, D. Jia, Z. Guo, RSC Adv., 3 (2013) 5003-5008.

[47] H. Kim, A.W. Robertson, S.O. Kim, J.M. Kim, J.H. Warner, ACS Nano, 9 (2015) 5947-5957.

[48] W. Bao, B. Yu, W. Li, H. Fan, J. Bai, Z. Ren, J. Alloys Compd., 647 (2015) 873-879.

[49] L. Duan, Y. Chen, K. Zhang, H. Luo, J. Huang, A. Xu, RSC Adv., 5 (2015) 84303-84310.

[50] D. Su, J. wang, H. Jin, Y. Gong, M. Li, Z. Pang, Y. Wang, J. Mater. Chem., A, 3 (2015) 11756-11761.

[51] L. Jia, D.A. Bulushev, O.Y. Podyacheva, A.I. Boronin, L.S. Kibis, E.Y. Gerasimov, S. Beloshapkin, I.A. Seryak, Z.R. Ismagilov, J.R.H. Ross, J. Catal., 307 (2013) 94-102.

[52] R.V. Jagadeesh, H. Junge, M.-M. Pohl, J. Radnik, A. Brückner, M. Beller, J. Am. Chem. Soc., 135 (2013) 10776-10782.

[53] F.A. Westerhaus, R.V. Jagadeesh, G. Wienhöfer, M.-M. Pohl, J. Radnik, A.-E. Surkus, J. Rabeah, K. Junge, H. Junge, M. Nielsen, A. Brückner, M. Beller, Nat. Chem., 5 (2013) 537-543. 
[54] D. Banerjee, R.V. Jagadeesh, K. Junge, M.-M. Pohl, J. Radnik, A. Brückner, M. Beller, Angew. Chem. Int. Ed., 53 (2014) $4359-4363$.

[55] R.V. Jagadeesh, H. Junge, M. Beller, Nat. Commun., 5 (2014).

[56] T. Stemmler, F.A. Westerhaus, A.-E. Surkus, M.-M. Pohl, K. Junge, M. Beller, Green Chem., 16 (2014) 4535-4540.

[57] R.V. Jagadeesh, D. Banerjee, P.B. Arockiam, H. Junge, K. Junge, M.-M. Pohl, J. Radnik, A. Bruckner, M. Beller, Green Chem., 17 (2015) $898-902$.

[58] R.V. Jagadeesh, T. Stemmler, A.-E. Surkus, M. Bauer, M.-M. Pohl, J. Radnik, K. Junge, H. Junge, A. Bruckner, M. Beller, Nat. Protocols, 10 (2015) 916-926.

[59] S. Pisiewicz, T. Stemmler, A.-E. Surkus, K. Junge, M. Beller, ChemCatChem, 7 (2015) 62-64.

[60] F.A. Westerhaus, I. Sorribes, G. Wienhöfer, K. Junge, M. Beller, Synlett, 26 (2015) 313-317.

[61] T. Stemmler, F. Chen, S. Pisiewicz, A.E. Surkus, M.M. Pohl, C. Topf, M. Beller, J. Mater. Chem., A, 3 (2015) 17728-17737.

[62] F. Chen, A.-E. Surkus, L. He, M.-M. Pohl, J. Radnik, C. Topf, K. Junge, M. Beller, J. Am. Chem. Soc., 137 (2015) $11718-11724$.

[63] M. Viganò, F. Ferretti, A. Caselli, F. Ragaini, M. Rossi, P. Mussini, P. Macchi, Chem. Eur. J., 20 (2014) 14451-14464.

[64] M. Viganò, F. Ragaini, M.G. Buonomenna, R. Lariccia, A. Caselli, E. Gallo, S. Cenini, J.C. Jansen, E. Drioli, ChemCatChem, 2 (2010) 1150-1164.

[65] M. Gasperini, F. Ragaini, S. Cenini, Organometallics, 21 (2002) 2950-2957.

[66] C. Graebe, E. Gfeller, Justus Liebigs Ann. der Chem., 276 (1893) 1-20.

[67] H.C. Rai, B.K. Rai, Asian J. Chem., 13 (2001) 264-268.

[68] F. Ragaini, M. Gasperini, P. Parma, E. Gallo, N. Casati, P. Macchi, New J. Chem., 30 (2006) 1046-1057.

[69] N.A.M. Barakat, B. Kim, S.J. Park, Y. Jo, M.-H. Jung, H.Y. Kim, J. Mater. Chem., 19 (2009) 7371-7378.

[70] L. Zhang, P. Hu, X. Zhao, R. Tian, R. Zou, D. Xia, J. Mater. Chem., 21 (2011) 18279-18283.

[71] F. Jaouen, J. Herranz, M. Lefèvre, J.-P. Dodelet, U.I. Kramm, I. Herrmann, P. Bogdanoff, J. Maruyama, T. Nagaoka, A. Garsuch, J.R. Dahn, T. Olson,

S. Pylypenko, P. Atanassov, E.A. Ustinov, ACS Appl. Mater. Inter., 1 (2009) 1623-1639.

[72] Q. He, Q. Li, S. Khene, X. Ren, F.E. López-Suárez, D. Lozano-Castelló, A. Bueno-López, G. Wu, J. Phys. Chem. C, 117 (2013) $8697-8707$.

[73] M.C. Biesinger, B.P. Payne, A.P. Grosvenor, L.W.M. Lau, A.R. Gerson, R.S.C. Smart, Appl. Surf. Sci., 257 (2011) $2717-2730$.

[74] M.B. Gawande, A. Goswami, T. Asefa, H. Guo, A.V. Biradar, D.-L. Peng, R. Zboril, R.S. Varma, Chem. Soc. Rev., 44 (2015) $7540-7590$.

[75] T. Kahl, K.-W. Schröder, F.R. Lawrence, W.J. Marshall, H. Höke, R. Jäckh, Aniline in: Ullmann's Encyclopedia of Industrial Chemistry, Wiley-VCH Verlag $\mathrm{GmbH} \& \mathrm{Co} . \mathrm{KGaA}, 2000$

[76] A.R. Cartolano, G.A. Vedage, Amines by reduction in: Kirk-Othmer Encyclopedia of Chemical Technology, John Wiley \& Sons, Inc., 2000.

[77] D.J. Dixon, O. Pando Morejón, Recent Developments in the Reduction of Nitro and Nitroso Compounds in: P. Knochel (Ed.) Comprehensive Organic Synthesis II (Second Edition), Elsevier, Amsterdam, 2014, pp. 479-492.

[78] H.-U. Blaser, H. Steiner, M. Studer, ChemCatChem, 1 (2009) 210-221.

[79] D. Formenti, C. Topf, K. Junge, F. Ragaini, M. Beller, Catal. Sci. Technol., 6 (2016) 4473-4477.

[80] E. Bamberger, J. Lagutt, Chem. Ber., 31 (1898) 1500-1508.

[81] H. Lund, Cathodic Reduction of Nitro and Related Compounds in: O.H. Henning Lund (Ed.) Organic Electrochemistry, CRC Press, New York, 2000.

[82] E. Müller, E. Lindemann, Angew. Chem., 46 (1933) 681-685.

[83] Y.-S. Choi, Y.-J. Kim, L.-L. Shen, Y.S. Lee, J.-H. Jeong, Synlett, 26 (2015) 970-974.

[84] A. Urios, M. Largeron, M.-B. Fleury, M. Blanco, Free Radical Biol. Med., 40 (2006) 791-800.

[85] H. Gao, J. Kawabata, Bioorg. Med. Chem. Lett., 18 (2008) 812-815.

[86] E. Kato, K. Oikawa, K. Takahashi, J. Kawabata, Biosci., Biotechnol., Biochem., 76 (2012) 1044-1046.

[87] E. Kato, H. Tsuji, J. Kawabata, Tetrahedron, 71 (2015) 1419-1424.

[88] B. Wen, K.J. Coe, P. Rademacher, W.L. Fitch, M. Monshouwer, S.D. Nelson, Chem. Res. Toxicol., 21 (2008) $2393-2406$.

[89] W. Herath, I.A. Khan, Chem. Pharm. Bull., 58 (2010) 562-564.

[90] C. Udagawa, S. Fukuyoshi, S. Morimoto, Y. Tanimoto, R. Nakagaki, J. Photochem. Photobiol., A, 226 (2011) 57-63.

[91] K.B. Borisenko, I. Hargittai, J. Phys. Chem., 97 (1993) 4080-4084.

[92] P.H. Matter, L. Zhang, U.S. Ozkan, J. Catal., 239 (2006) 83-96.

[93] G. Faubert, R. Côté, J.P. Dodelet, M. Lefèvre, P. Bertrand, Electrochim. Acta, 44 (1999) 2589-2603.

[94] D. Guo, R. Shibuya, C. Akiba, S. Saji, T. Kondo, J. Nakamura, Science, 351 (2016) 361-365.

[95] J.V.H. d'Angelo, A.Z. Francesconi, J.Chem. Eng. Data, 46 (2001) 671-674.

[96] E. Brunner, Berichte der Bunsengesellschaft für physikalische Chemie, 83 (1979) 715-721.

[97] K. Radhakrishnan, P.A. Ramachandran, P.H. Brahme, R.V. Chaudhari, J. Chem. Eng. Data, 28 (1983) 1-4.

[9895] M. Fang, N. Machalaba, R.A. Sanchez-Delgado, Dalton Trans., 40 (2011) 10621-10632.

[9996] M. Fang, R.A. Sánchez-Delgado, J. Catal., 311 (2014) 357-368.

[10097] A. Sánchez, M. Fang, A. Ahmed, R.A. Sánchez-Delgado, Appl. Catal., A, 477 (2014) 117-124.

[10198] U.I. Kramm, I. Herrmann-Geppert, J. Behrends, K. Lips, S. Fiechter, P. Bogdanoff, J. Am. Chem. Soc., 138 (2016) 635-640.

[10299] A. Zitolo, V. Goellner, V. Armel, M.-T. Sougrati, T. Mineva, L. Stievano, E. Fonda, F. Jaouen, Nat. Mater., 14 (2015) $937-942$.

[103100] T. Cheng, H. Yu, F. Peng, H. Wang, B. Zhang, D. Su, Catal. Sci. Technol., 6 (2016) 1007-1015.

[104101] W. Liu, L. Zhang, W. Yan, X. Liu, X. Yang, S. Miao, W. Wang, A. Wang, T. Zhang, Chem. Sci., 7 (2016) 5758-5764.

[105102] C.E. Szakacs, M. Lefevre, U.I. Kramm, J.-P. Dodelet, F. Vidal, PCCP, 16 (2014) 13654-13661.

[106103] B. Li, X. Sun, D. Su, PCCP, 17 (2015) 6691-6694.

[107104] It should be stressed that the conclusions on the identity of the active site reached in this paper holds for the presently discussed system, although they may be more general. However, they are not supposed to be universally true for any catalyst derived by a thermal degradation of a metal complex 
precursor. Graphitic catalysts have also been generated by other groups with different procedures (see cited references), but their structure can be very different from that of ours. For example, very recently, Corma and coworkers investigated a catalyst prepared by reduction under dihydrogen of a material obtained by reacting cobalt nitrate with EDTA [L. Liu, P. Conception, A. Corma, J. Catal.,140 (2016) 1-9]. The catalytic activity was attributed to metallic cobalt and the role of carbon was identified as that of preventing metal over-oxidation, a conclusion opposite to that reached by us. However, Corma's catalyst and ours are markedly different. Most notable differences are: a) Corma's catalyst contains much lesser carbon than ours (cobalt constitutes $95 \%$ of the mass of his catalyst, whereas it is $\sim 3 \%$ in ours); b) the carbon is mostly graphitic in our catalyst and mostly amorphous in Corma's catalyst; c) most importantly, no nitrogen is present in Corma's catalyst after it has been activated, whereas nitrogen plays a key role in our system. Thus, it is clear that the two catalysts are not comparable, even if similarities exist in their preparation, and it is not surprising that the catalytically active sites differ. 